\title{
Effect of a weightlifting belt on spinal shrinkage
}

\author{
N. D. Bourne and T. Reilly \\ Centre for Sport and Exercise Sciences, School of Health Sciences, Liverpool Polytechnic, Byrom Street, \\ Liverpool L3 3AF, UK
}

\begin{abstract}
Spinal loading during weightlifting results in a loss of stature which has been attributed to a decrease in height of the intervertebral discs - so-called 'spinal shrinkage'. Belts are often used during the lifting of heavy weights, purportedly to support, stabilize and thereby attenuate the load on the spine. The purpose of this study was to examine the effects of a standard weightlifting belt in attenuating spinal shrinkage. Eight male subjects with a mean age of $\mathbf{2 4 . 8}$ years performed two sequences of circuit weight-training, one without a belt and on a separate occasion with a belt. The circuit training regimen consisted of six common weight-training exercises. These were performed in three sets of ten with a change of exercise after each set of ten repetitions. A stadiometer sensitive to within $0.01 \mathrm{~mm}$ was used to record alterations in stature. Measurements of stature were taken before and after completion of the circuit. The absolute visual analogue scale (AVAS) was used to measure the discomfort and pain intensity resulting from each of the two conditions. The circuit weight-training caused stature losses of $3.59 \mathrm{~mm}$ without the belt and $2.87 \mathrm{~mm}$ with the belt $(P>0.05)$. The subjects complained of significantly less discomfort when the belt was worn $(P<0.05)$. The degree of shrinkage was significantly correlated $(r=0.752$, $P<0.05)$ with perceived discomfort but only when the belt was not worn. These results suggest the potential benefits of wearing a weightlifting belt and support the hypothesis that the belt can help in stabilizing the trunk.
\end{abstract}

Keywords: Weightlifting belt, spinal shrinkage, circuit training

Weightlifting belts are marketed commercially with the aim of preventing back injuries while lifting heavy weights. It is thought that they do so by helping to support and stabilize the spine. They may also have an effect upon intra-abdominal pressure, the mechanism widely held responsible for reducing spinal compressive forces ${ }^{1}$.

Harman et al. ${ }^{2}$ and Lander et al. ${ }^{3}$ have analysed the effect of a weightlifting belt during performance of the dead-lift and squat, respectively. Results confirmed that a weightlifting belt can aid in supporting the trunk by increasing intra-abdominal pressure.

McGill et al. ${ }^{4}$ examined the effects on intraabdominal pressure of wearing abdominal belts as prescribed to industrial workers. Subjects demonstrated a significant increase in intra-abdominal pressure on wearing the belt (compared with lifting

Address for correspondence: Professor T. Reilly

(C) 1991 Butterworth-Heinemann Ltd

0306-3674/91/040209-04 without a belt) while lifting loads of $72.7-90.9 \mathrm{~kg}$, both with the breath held and continuously expiring on the lifting effort. Wearing a belt did not augment the reduction in muscle activity of the erector spinae when lifting with the breath held.

Spinal loading during weightlifting is reflected in changes of stature, a phenomenon known as 'shrinkage'. The loss of height is due to extrusion of water through the disc wall when the applied compressive force exceeds the imbibition pressure of the nucleus pulposus complex and the osmotic gradient across the disc membranes ${ }^{5}$. Shrinkage is measured using a purpose-built stadiometer: the technique has been applied successfully in studies of weightlifting 6,7 , in ergonomics ${ }^{8,9}$, and sports training (Leatt et al. ${ }^{10}$ on running and Boocock et al. ${ }^{11}$ on plyometrics). Shrinkage, as an index of spinal loading, allows further investigation of the effectiveness of a weightlifting belt in attenuating the load on the spine. The purpose of this study was to investigate the effect of a standard weightlifting belt on spinal shrinkage during circuit weight-training. Six common weight-training exercises were chosen which load the spine to differing degrees.

\section{Patients and methods}

Eight men aged mean(s.d.) 24.8(2.3) years, weighing mean(s.d.) 73.1(5.7) $\mathrm{kg}$ and measuring mean(s.d.) $175.5(7.2) \mathrm{cm}$ in height acted as subjects. All were experienced (5.75 years) in the use of weights but not in competitive weightlifting. They did not habitually wear belts when training. Before participating, subjects filled in voluntary consent forms: subjects with a history of back pain or neurological disorder were excluded from the study. The project was approved by the Ethics Committee of Liverpool Polytechnic.

Measurements of stature were carried out using a stadiometer as described by Boocock et al. ${ }^{11}$. The equipment is illustrated in Figure 1. The stadiometer was sensitive to within $0.01 \mathrm{~mm}$.

The angle of inclination of the stadiometer was $13^{\circ}$, thus eliminating in large part the muscular effort required to maintain the body in an upright position. A BBC microcomputer was interfaced with the stadiometer, providing 'on-line' data capture. To use the stadiometer the subjects were first familiarized with the apparatus. This took on average 50-60 $\mathrm{min}$ until each subject obtained a standard deviation of less than $0.5 \mathrm{~mm}$ in ten consecutive measurements. 
For each subject to undergo a standardized weight-training protocol, the ten repetition maximum (10RM) criterion was used ${ }^{12}$. This meant that, for each exercise, the predetermined 10RM load was lifted ten times. Six common weight-training exercises were specifically chosen to load the spine to varying degrees. These were carried out in the form of a circuit which consisted of three sets of ten repetitions with a change of exercise after each set of ten. The order in which the exercises were performed and the mean loads lifted are shown in Table 1.

Individual 10RM scores were determined by direct practice of a set or sets of ten repetitions of increasing load until the precise weight was obtained. This had three major advantages: (1) it enabled an exact determination of the 10RM; (2) it represented a commonly used number of repetitions recommended for strength improvement; and (3) it accustomed the subjects to performing an average of two to three sets of each exercise.

The subjects underwent two weight-training sessions on separate occasions, with at least 5 days, and on average 7 days, separating them. Measurements for each individual were taken at the same time of day $(15.30-18.30 \mathrm{~h})$ to control for circadian variation in stature ${ }^{6,7}$. Subjects were instructed to follow their normal daily routine, avoiding any excessive physical or sporting activity on the day of testing.

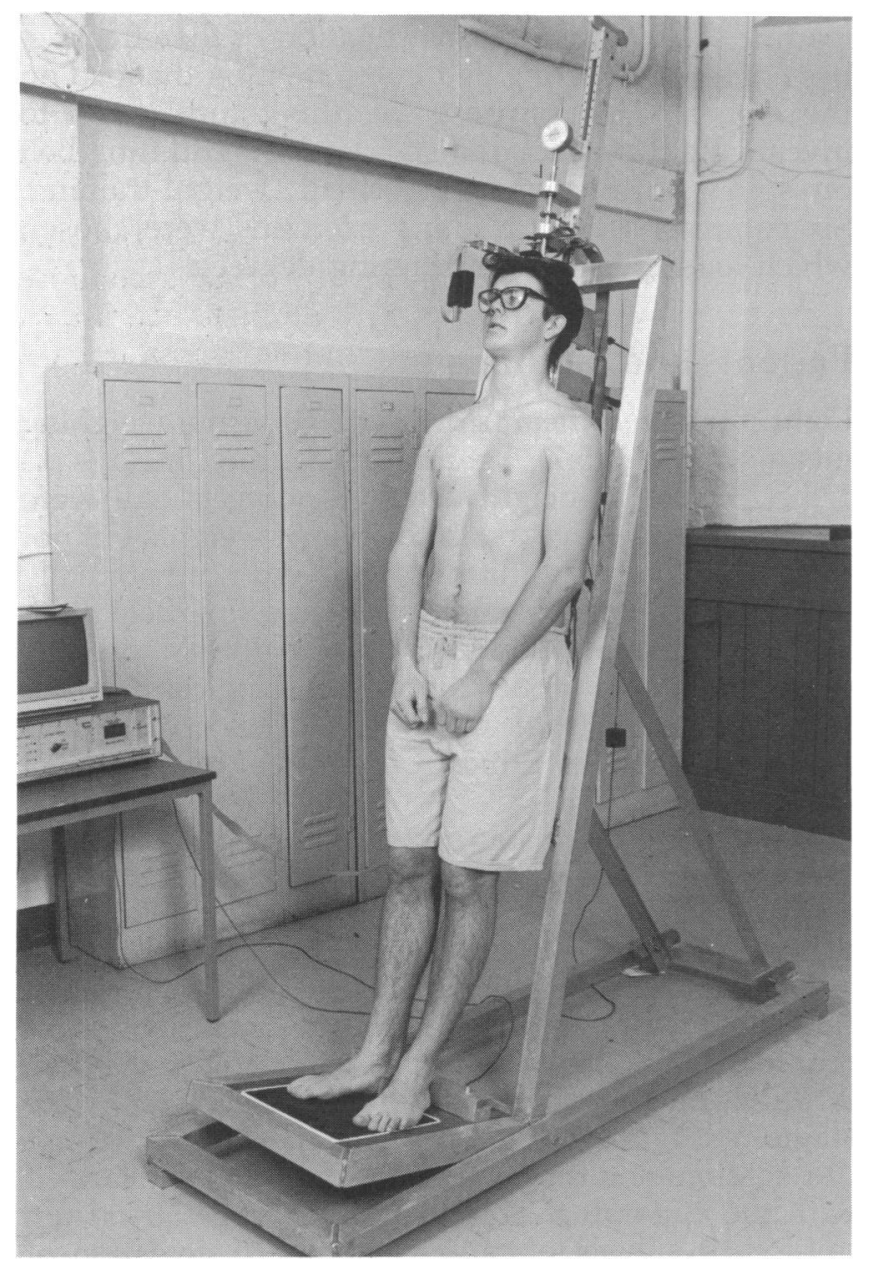

Figure 1. Stadiometer - apparatus for measuring stature
On the days of measurement, before beginning the circuit, the subjects were required to stand for a period of $20 \mathrm{~min}$ with their weight evenly distributed. This attempted to standardize and control for any spinal loading or unloading that may have directly preceded testing ${ }^{11}$. Following this period, each subject was measured on the stadiometer. Five consecutive measurements were recorded, with the computer program calculating the mean value.

The circuit training followed immediately, with each subject being randomly assigned to lift first with, or without, the belt. The weightlifting belt was chosen for its approximation to the belt used by Harman et $a .^{2}$ and is typical of those used by recreational weightlifters. It consists of a single layer of leather $5 \mathrm{~mm}$ thick, being $120 \mathrm{~cm}$ long, $152 \mathrm{~mm}$ wide in its centre section and tapering to $51 \mathrm{~mm}$ at either end. The belt was worn with the thickest portion positioned over the lumbar spine. The belt was tightened fully for each individual, allowing for comfort and ease of respiratory movement.

Observation and verbal input during the circuit ensured that all lifts were performed according to standard technique. A 2-min rest was taken at the completion of the first and second set of six exercises. The mean(s.d.) duration of the total exercise period was 32.6(5.8) min (with belt) and 31.4(4.0) $\mathrm{min}$ (without belt).

The subjects' breathing had returned to normal within $3 \mathrm{~min}$ of completing the circuit. This allowed measurements to be performed after exercise on the stadiometer at that time (i.e. $3 \mathrm{~min}$ after exercise).

In addition to measurement of stature, the absolute visual analogue scale (AVAS) was used as a measure of discomfort and pain intensity ${ }^{13}$. The AVAS scale consisted of a $20-\mathrm{cm}$ horizontal line with the headings of no discomfort-pain at either end. Each individual's subjective rating of pain/discomfort was marked off before and after completion of the circuit with no opportunity to compare values with previous estimates.

\section{Statistical analysis}

Differences in shrinkage occurring while wearing a belt and between degrees of discomfort and pain were examined using $t$ tests. Correlations between back discomfort and degree of shrinkage along with weights lifted (10RM) and degree of shrinkage were examined using the Pearson Product Moment correlation coefficient.

Table 1. The order of exercises performed and load lifted

\begin{tabular}{lll}
\hline Order & \multicolumn{1}{c}{ Exercise } & Load $(\mathrm{kg})$ \\
\hline 1 & Dead-lift & $51.1(13.4)$ \\
2 & High pull & $32.1(4.8)$ \\
3 & Squat & $61.1(20.5)$ \\
4 & Clean & $37.4(6.8)$ \\
5 & Bent-over rowing & $32.1(5.7)$ \\
6 & Biceps curls & $26.8(5.7)$ \\
\hline
\end{tabular}

Values of load are mean(s.d.) 


\section{Results and discussion}

Mean(s.d.) alterations in stature for the two conditions, with and without a belt, are given in Table 2. Six of eight subjects showed greater shrinkage without the belt. Despite the greater absolute mean loss in height $(0.72 \mathrm{~mm})$ for the condition with no belt, the difference in shrinkage between the two conditions was not significant $(P>0.05)$.

Comparison of discomfort experienced in the two conditions revealed significantly less discomfort $(P<0.05)$ for the belt condition. This reduction in discomfort through wearing the belt may reflect its protective function.

The higher pain values in the 'no belt' condition were due mainly to raised levels of pain in only two subjects. No reason was apparent for this response. The two most experienced lifters had no complaints of pain or discomfort under either condition.

In the 'no belt' condition, perceived discomfort was significantly correlated with height loss $(r=0.752$, $P<0.05)$, but this relationship was not significant when the belt was worn $(r=0.596, P>0.05)$. Height lost when not using the belt was not significantly correlated with the weight lifted (10RM) for either the squat $(r=0.42, \quad P>0.05)$ or the dead-lift $(r=0.37$, $P>0.05$ ). It is possible that individual variation in the loads lifted by each subject and variations in efficiency of technique contributed to this lack of significance. As a prerequisite for inclusion in the study, and for obvious reasons of safety, the subjects were all experienced in the use of weights. However, individuals had different levels of experience in lifting as well as different 10RM values. Those subjects who had the higher 10RM values may have been better able to compensate for spinal loading by greater muscle strength. Wilby et al. ${ }^{7}$ showed that height losses were inversely correlated with isometric back strength in female subjects.

The mean shrinkage values observed in this study were less than those previously observed despite the similarities in regimen and exercise duration. Wilby $e t$ $a .^{7}$ and Leatt et al. ${ }^{10}$ both reported a mean loss of $5.4 \mathrm{~mm}$ during circuit weight-training for 20-min and 25-min exercise periods, respectively. It is possible that the greater experience and skill of subjects in this study contributed to the lower shrinkage. The time of day may also have contributed to the lower values in the present study: Wilby et al. ${ }^{7}$ have shown that the greatest shrinkage owing to weight-training occurs first thing in the morning.

Table 2. Shrinkage, perceived discomfort and pain for the two conditions (with belt and no belt)

\begin{tabular}{lrr}
\hline Effect & \multicolumn{2}{c}{ Condition } \\
\cline { 2 - 3 } & With belt & No belt \\
\hline Shrinkage (mm) & $2.9(1.65)$ & $3.6(3.3)$ \\
Perceived discomfort & $16.6(15.2)$ & $63.4(58.7)$ \\
Perceived pain & $0.8(2.12)$ & $8.9(16.9)$ \\
\hline
\end{tabular}

Values are mean(s.d.)
Furthermore, a possible explanation for the failure of the effect of the weightlifting belt to reach significance can be gained by examining the findings of Harman et al. ${ }^{2}$ and Lander et al. ${ }^{3}$ on the effects of a weightlifting belt upon intra-abdominal pressure. Lander et $a l^{3}{ }^{3}$ found that most differences were observed during the $90 \%$ maximum lift (1RM) condition. As the $10 \mathrm{RM}$ represents about $61 \%$ of the $1 \mathrm{RM}^{14}$, it is possible that the significant effect of increasing intra-abdominal pressure may not occur to the same extent during repetitions of the 10RM. The belt may, however, have a cumulative protective effect when used when lifting weights of submaximal load with a high number of repetitions.

The extent that the weightlifting belt increases intra-abdominal pressure in particular exercises, apart from the squat and dead-lift, remains to be investigated. Possible benefits of the belt during the squat and dead-lift may have been obscured by the other exercises in the circuit.

While it has been demonstrated that the use of a weightlifting belt significantly increases intraabdominal pressure ${ }^{2-4}$, the exact mechanism through which this increase may attenuate the load on the spine remains to be defined. What is apparent is the significant effect of a weightlifting belt in reducing discomfort as found in this study along with improving perceptions of trunk stability ${ }^{4}$.

In summary, the main findings of this study were as follows.

1. The circuit weight-training regimen was found to induce stature losses of $3.59 \mathrm{~mm}$ without the belt and $2.87 \mathrm{~mm}$ with the belt. Despite the greater absolute mean loss of height $(0.72 \mathrm{~mm})$ for the 'no belt' condition, the difference did not reach significance $(P>0.05)$.

2. Comparison of discomfort experienced in the two conditions revealed significantly less discomfort $(P<0.05)$ in the weightlifting 'with belt' condition. This suggests that the belt afforded some protection.

3. The amount of shrinkage was significantly correlated $(r=0.752, P<0.05)$ with perceived discomfort, but this was observed only in the weightlifting condition with 'no belt'.

Wearing a weightlifting belt tends to induce less absolute spinal shrinkage and causes significantly less discomfort compared to lifting without a belt. These observations suggest the potential benefits of wearing a weightlifting belt and support the hypothesis that the belt can help in stabilizing the trunk.

\section{Acknowledgements}

The authors are grateful to Dr J. D. G. Troup for his valuable comments in the early stages of this study.

\section{References}

1 Bartelink DL. The role of abdominal pressure in relieving pressure on the lumbar intervertebral discs. J Bone Joint Surg [Br] 1957; 39: 718-25.

2 Harman EA, Rosenstein RM, Frykman PN, Nigro GA. Effects of a belt on intraabdominal pressure. Med Sci Sports Exer 1989;
21: 186-90. 
3 Lander JE, Simonton RL, Giacobbe JKF. The effectiveness of weight-belts during the squat exercise. Med Sci Sports Exer 1990; 22: 117-26.

4 McGill SM, Norman RW, Sharratt MT. The effect of an abdominal belt on trunk muscle activity and intra-abdominal pressure during squat lifts. Ergonomics 1990; 33: 147-60.

5 Troup JDG, Reilly T, Eklund JAE, Leatt P. Changes in stature with spinal loading and their relation to the perception of exertion or discomfort. Stress Med 1986; 1: 303-7.

6 Tyrrell AR, Reilly T, Troup JDG. Circadian variation in stature and the effects of spinal loading. Spine 1985; 10: 161-4.

7 Wilby J, Linge K, Reilly T, Troup JDG. Spinal shrinkage in females: circadian variation and the effects of circuit weight-training. Ergonomics 1987; 30: 47-54.

8 Eklund JAE, Corlett N. Shrinkage as a measure of the effect of load on the spine. Spine 1984; 9: 188-94.
9 Corlett EN, Eklund JAE, Reilly T, Troup JDG. Assessment of workload from measurement of stature. Appl Ergonom 1987; 18: $65-71$.

10 Leatt $\mathrm{P}$, Reilly T, Troup JDG. Spinal loading during circuit weight-training and running. Br J Sp Med 1986; 20: 119-24.

11 Boocock MG, Garbutt G, Reilly T, Linge K, Troup JDG. The effects of gravity inversion on exercise induced spinal loading. Ergonomics 1988; 31: 1631-7.

12 Klausen K. Strength and weight training. In: Reilly T, Secher N, Snell P, Williams C, eds. Physiology of Sports. London: E and FN Spon, 1990: 41-67.

13 Zusman M. The absolute visual analogue scale (AVAS) as a measure of pain intensity. Aust J Physiother 1986; 32: 244-6.

14 McDonagh MJN, Davies CTM. Adaptive response of mammalian skeletal muscle to exercise with high loads. Eur J Appl Physiol 1984; 52: 139-55. 